\title{
Metabolic Profile and the Risk of Early Atherosclerosis in Patients with Obesity and Overweight
}

\author{
TEODORA GABRIELA ALEXESCU1*, IOANA ROXANA BORDEA², ANGELA COZMA ${ }^{1}$, RUXANDRA RAJ NOVEANU3, \\ ANCA DANA BUZOIANU 4 , ROXANA MARIA NEMES ${ }^{5}$, SORIN IOAN TUDORACHE ${ }^{6}$, BEATRICE MAHLER BOCA \\ DOINA ADINA TODEA ${ }^{3}$ \\ ${ }^{1}$ Iuliu Hatieganu University of Medicine and Pharmacy, Department of Internal Medicine, 4 Louis Pasteur Str., 400349, \\ Cluj-Napoca, Romania \\ ${ }^{2}$ Iuliu Hatieganu University of Medicine and Pharmacy, Department of Management, Health and Oral Rehabilitation, 4 Louis \\ Pasteur Str., 400349, Cluj Napoca, Romania \\ ${ }^{3}$ Iuliu Hatieganu University of Medicine and Pharmacy, Department of Pneumology, 4 Louis Pasteur Str., 400349, Cluj Napoca, \\ Romania \\ ${ }^{4}$ Iuliu Hatieganu University of Medicine and Pharmacy, Department of Pharmacology, 4 Louis Pasteur Str., 400349, Cluj Napoca, \\ Romania \\ ${ }^{5}$ Titu Maiorescu University, Faculty of Medicine, Department of Physiopathology, 22 Dambovnicului Str, 031593, Bucharest, \\ Romania \\ ${ }^{6}$ Titu Maiorescu University, Faculty of Medicine, Department of Anatomy, 22 Dambovnicului Str, 031593, Bucharest, Romania \\ ${ }^{7}$ Carol Davila University, Faculty of Medicine, Department of Pneumology, 8 Eroii Sanitari Blvd, 020021, Bucharest, Romania
}

\begin{abstract}
Obesity and Overweight have the highest rate of incidence and prevalence in the past 3 decades, as global pathologies. The purpose of this study was to evaluate cardiovascular, classic and modern risk factors in overweight and obese patients by studying lipid metabolism (total cholesterol, HDL-cholesterol, non-HDLcholesterol, LDL-cholesterol, serum triglycerides), glucose metabolism, insulin resistance and insulin sensitivity, the prevalence of hypertension (HBP) and the prevalence of metabolic syndrome (MS). This analytical study was performed on 111 subjects divided as follows: Group I consisting of 27 normal weight subjects - NW; Group II consisting of 84 overweight and obese subjects - OW + 0: 36 overweight patients - OW; 33 patients with grade I obesity - 0-I; 13 patients with grade II obesity - 0-II; 2 patients with grade III obesity- O-III. The overweight and obese, although unknown with heart disease, have significant metabolic changes, such as atherogenic dyslipidemia, dysglycemia, high insulin resistance and low insulin sensitivity, metabolic syndrome, these being the first steps towards endothelial dysfunction and early atherosclerosis.
\end{abstract}

Keywords: obesity, metabolism changes, insulinoresistance, overweight

Overweight and obesity have come to rank fifth in the world in mortality rates, especially through associated comorbidities [1]. The prevalence of obesity has doubled or even tripled in less than two decades, becoming a concern in children, with percentages as high as $36 \%$ in some regions of Europe [2]; in 2013, two-thirds of adult North Americans are overweight, a third being obese [3] Epidemiological data from 2016 look extremely worrying: over 1.9 billion adults are overweight (39\%), over 650 million with obesity (13\%); 41 million children under 5 are overweight or obese and over 340 million children and adolescents aged 5-19 years [4]. In Romania, the ORO study results show an obesity rate of $21.3 \%$ and a prevalence of overweight of $31.1 \%$ in subjects aged $18-79$ [5]. Thus, obesity affects $23 \%$ of men, compared to $20.3 \%$ of women, while overweight $41.6 \%$ of males compared to $24.7 \%$ of women [5].

Obesity, especially visceral abdominal obesity, leads to a number of systemic metabolic and inflammatory complications, with important implications in the pathogenesis of cardiovascular disorders: atherogenic dyslipidemia (LDL cholesterol increased, hypertriglyceridemia, low HDL-cholesterol, apolipoprotein B increase and VLDL); deterioration of plasma glucose and insulin (hyperglycaemia, dysglycemia, insulin resistance); adipokine release (hypercoagulability, increase in inflammatory markers); impairment of endothelial function; increased oxidative stress [6-8].

Obesity risks can be classified into two broad categories according to pathogenetic mechanisms, most often interrelated: the risks arising from the mechanical effects of fatty tissue, but especially the risks arising from systemic metabolic and inflammatory changes associated with the secretion of various adipokins by pathological adipose tissue [6].

\section{Experimental part}

This was an experimental study conducted in the CF University Hospital, Cluj-Napoca, Romania. The subjects included in the study were randomly selected from about 7500 patients admitted to the Medical Department of the CF Clinical Hospital Cluj-Napoca in the period of two years. A systematic random sampling method was used. All the patients selected by this method were included in the study, after meeting the ethical criteria of presence of an informed consent to participate in the study and also the absence of a diagnosis and/or clinical complaints of heart disease or any diagnosis interfering with survival over the next 2 years. The study, conducted on human subjects, had the approval of the Medical Ethics Committee, and each subject signed an informed consent according to current legislation.

This analytical study was performed on 111 subjects divided as follows: Group I consisting of 27 normal weight subjects - NW; Group II consisting of 84 overweight and obese subjects - OW + 0: 36 overweight patients - OW; 33 patients with grade I obesity - 0-I; 13 patients with grade II obesity - 0-II; 2 patients with grade III obesity - 0III.

Exclusion criteria: subjects with a diagnosis or complaints of heart disease were excluded from the study. 
The purpose of the studywas to evaluate cardiovascular, classic and modern risk factors in overweight and obese patients by studying: lipid metabolism: total cholesterol, HDL-cholesterol, non-HDL-cholesterol, LDL-cholesterol, serum triglycerides; studying glucose metabolism; studying insulin resistance and insulin sensitivity; the prevalence of hypertension (HBP) and the prevalence of metabolic syndrome (MS) in these subjects.

Each participant was given a research report that included: personal data, personal pathological history, heredocolateral antecedents, anthropometric data: weight, height, abdominal circumference, medication used, smoking habits and consumption of alcoholic beverages, physical activity, data on eating habits, data on carbohydrate metabolism: glucose tolerance ( $\mathrm{VN}=80$ $100 \mathrm{mg} \%$ ), glucose tolerance test in those subjects with indication with the KONELAB 60i apparatus, enzymatic method, lipid metabolism data: total cholesterol (VN <100 mg\%), non-HDL-cholesterol (VN $\leq 130 \mathrm{mg} \%$ ), HDL cholesterol (VN> $40 \mathrm{mg} \%$ serum triglycerides (VN $<150$ $\mathrm{mg} \%$ ), the KONELAB 60i by enzyme method, blood pressure measurement, both arm and ankle (VN <140/90 $\mathrm{mmHg}$ ), serum insulin (CMIA method, $\mathrm{VN}=2.6-24.9 \mathrm{uUI}$ / $\mathrm{mL})[9,10]$.

Patients were stratified in 3 classes by body mass index $(B M I):\left(B M I=18.5-24.9 \mathrm{~kg} / \mathrm{m}^{2}\right)$, overweight $(I M C=25.0$ $\left.-29.9 \mathrm{~kg} / \mathrm{m}^{2}\right)$ and obese $\left(B M I \geq 30 \mathrm{~kg} / \mathrm{m}^{2}\right)$.

The abdominal circumference $(\mathrm{AC})$ was measured, according to the standards, halfway between the coastline and the upper iliac crest at the level of the mean axillary line at the end of a normal expiration [11].

The metabolic syndrome was defined, according to the consensus of the world's cardiovascular disease study societies in 2009, by the presence of any of three of the following five criteria: waist circumference greater than $94 \mathrm{~cm}$ in men and over $80 \mathrm{~cm}$ in women, blood pressure $\geq 130$ / $85 \mathrm{mmHg}$ or antihypertensive therapy, fasting blood glucose $\geq 100 \mathrm{mg} \%$ or type 2 diabetes diagnosis, serum triglycerides $\geq 150 \mathrm{mg}$ or therapy antidyslipidemic, HDLcholesterol values $\leq 40 \mathrm{mg} \%$ in men and $\leq 50 \mathrm{mg} \%$ in women or $\uparrow \mathrm{HDL}$-cholesterol therapy [12].

Matthews' HOMA-IR index (homeostasis model assessment of insulinresistance), which measures insulin resistance, was calculated based on the formula: basal insulinemia $(\mu \mathrm{U} / \mathrm{mL}) \times$ basal glycaemia $(\mathrm{mg} \%)$ / 405, with normal values <2.5 [13]. The QUICKI (Quantitative Insulin Sensitivity Check Index) score gives the measure of insulin sensitivity and was calculated according to the formula: QUICKI $=1 /[\log 10$ (insulin $(\mu \mathrm{L} / \mathrm{mL}))+\log 10$ (glycemia $(\mathrm{mg} / \mathrm{dL})$ ], assuming that at its values $\leq 0.33$ we can safely speak of insulin resistance [14]. The McAuley score (MCA), also measures insulin sensitivity and is calculated by the following equation $=\exp [2.63-0.28 \mathrm{In}$ (insulin in $\mathrm{mU} / \mathrm{L}$ ) - $0.31 \mathrm{In}$ (triglyceridemia in $\mathrm{mmol} / \mathrm{L}$ )]; pathological values being at a McAuley score $\leq 5.8$ [15].

The statistical analysis was performed using SPSS 13.0 for Windows and Microsoft Excel. We tested the normal distribution of continuous numeric variables using the Kolmogorov-Smirnov and Shapiro-Wilk tests. The differences between the means of the continuous quantitative variables were assessed using the Student ( $t$ test) test, respectively ANOVA (in the case of the presence of several categories). The analysis of the differences between the means of the continuous variables whose distribution does notmeet the normality condition was done with the help of the Mann-W hitney $U$ test, respectively the Kruskal Wallis one, in the case of the presence of several categories. To analyze the differences between the qualitative variables, the Z (Z-test) test and the Chi squared test $(\chi 2)$ were used $\chi$.

A value of $p<0.05$ was considered statistically significant.

\section{Results and discussions}

The study of lipid metabolism in overweight and obese patients

Lipid metabolism was studied in overw eight and obese patients compared to normoponderal and detailed levels of obesity, comparing the means of the following indicators: total serum cholesterol, HDL-cholesterol, non-HDLcholesterol, LDL-cholesterol, serum triglycerides. The Kolmogorov-Smirnov test confirms the normal distribution of the continuous variables characterizing lipid metabolism and thus allows the t test to verify whether the differences between the means of the lipid metabolism indicators are significant in overweight and obese compared to normoweights.

Although the meanmean serum triglycerides level is higher in the OW +0 vs NW group, a $p<0.05$ value is significant only for HDL-cholesterol, with normoponderal values having a significantly higher mean value.

To study lipid metabolism, a second method of analysis was used to compare the proportion of patients for whom the values of the lipid metabolism indicators are outside of the standard norms for normal weight individuals (NW) compared to overweight and obese $(\mathrm{OW}+0)$ and on degrees of obesity.

In the case of serum triglyceride mean values, the Chisquare test indicates a double percentage, statistically higher ( $p<0.05$ ) than normal (VN <150 mg\%) in the OW +0 group compared to NW. Atherogenic dyslipidemia is a well-known component of patients with metabolic syndrome but is also recognized as a traditional factor of modifiable cardiovascular risk [16, 17]. Dyslipidemia also appears in the panel of metabolic complications of obesity [11]. Atherogenic dyslipidemia involves elevated LDL cholesterol, triglyceridemia, low HDL-cholesterol, apolipoprotein B and / or VLDL elevation, increased serum $\mathrm{HDL}$-cholesterol being recently included in this series and offering an easy clinical estimate of rich cholesterol in atherogenic particles, including IDL, VLDL, Lp (a), LDL, apoB100, apoC1 [18].

HDL-cholesterol is a lipid particle formed mostly of cholesterol, phospholipids and proteins, produced and secreted by the liver and intestine [19, 20]. HDL-cholesterol protects the individual against atherogenesis by antiinflammatory, anticoagulant, antioxidant, antiaggregant, and profibrinolytic properties [21-23]. High levels of HDLcholesterol are desirable because of their inverse relationship with the risk of atherosclerosis and the risk of coronary artery disease, HDL-cholesterol being the socalled good cholesterol [23, 24]. In our study we found that there is a downward trend in the mean value of HDLcholesterol in terms of weight gain, respectively as the rate of obesity increases; statistically significant differences $(p<0.05)$ on mean values of HDL-cholesterol observed between both normoponderal and overweight and obese, and between grade I and Normoponderal obese and obese grade II obese, but also between overweight and obese grade I.

Hypertriglyceridemia is a well-known defining element of metabolic syndrome at values exceeding $150 \mathrm{mg} \%$, insulin resistance-associated atherogenic marker [12]. It is also proven that in obesity, excess triglycerides in the liver ( fatty liver - hepatic steatosis), skeletal muscles and visceral 
adipocytes with abnormal adipocyte growth lead to insulin resistance and metabolic syndrome with increased cardiovascular risk [25, 26]. In a recent meta-analysis, an important correlation between body mass index and serum triglyceride level was reported after adjusting the data by age, gender, race, smoker status, or the amount of alcohol consumed daily [27]. In our study, mean serum triglycerides were elevated over the upper limit of normal $(\geq 150 \mathrm{mg} \%)$ in all obesity categories, with statistical significance $(p<0.05)$ in the proportion of overweight and obese over the proportion of normoponderal ( $51 \%$ versus $26 \%$ ). Smoking cessation is very important for obese smoker patients.[28, 29,30]

The study of carbohydrate metabolism in overweight and obese patients.

In $42 \%$ of obese and overweight patients, a change in carbohydrate metabolism (basal altered blood glucose, glucose tolerance, diabetes mellitus) occurs as opposed to only $22 \%$ in normoponderal patients (fig. 1).

Analyzing in detail, on subgroups of weight status, the prevalence of diabetes in patients with grade II and III obesity is statistically significantly higher $(p<0.05)$ than in normoponderal patients. Also, an almost doubling of the percentage of patients with grade I obesity $(27 \%)$ with basal altered glycemia versus normoponderal (15\%) is observed.

To study the incidence of insulin resistance in overweight and obese patients with glucose metabolism disorder, two methods were used:

-The mean values of insulin resistance and insulin sensitivity scores (HOMA-IR, TGL / HDL-Col, QUICKI, McAuley score) were compared in overweight and obese patients with glucose metabolism disorder compared to the rest of the batch-(fig. 2);
- The percentage of patients with pathological values in insulin resistance and insulin sensitivity scores (HOMA-IR, TGL / HDL-col ratio, QUICKI, McAuley score) was calculated and then studied whether this percentage was increased in overweight and obese metabolic disorders carbohydrate compared to the rest of the batch- Figure 3.

Applying the Mann-Whitney test, the mean values of HOMA-IR insulin resistance scores are highly statistically significant $(p<0.001)$ and TGL/HDL-col ratio statistically significant $(p<0.05)$ higher in overweight and obese patients with modified carbohydrate metabolism im compatison to the remainder of the batch and are significantly less significant $(p<0.001)$ and statistically significant $(p<0.05)$ for the mean values of the QUICKI and McAuley insulin sensitivity scores respectively. The percentage of overweight and obese patients with pathological metabolic disorders is significantly higher than their percentage in the rest of the batch for three out of four insulin resistance and insulin sensitivity scores: HOMA-IR, QUICKI and McAuley.

In the present study, overweight and obese patients have a $42 \%$ change in carbohydrate metabolism (basal altered blood glucose, altered glucose tolerance, type 2 diabetes), noting that $46 \%$ of those with grade II obesity and $50 \%$ those with grade III obesity have diabetes, compared with only $7 \%$ normoponderal and 18\% overweight ( $p<0.05$ ). Also, the percentage of patients with basal altered blood glucose is double in subjects with grade I obesity compared to normoponderal subjects.

The Nurse's Health study [31], a 20-year follow-up study on 121,700 women aged 30-55 years, found that the risk of developing type 2 diabetes was 49 times higher among women whose body mass index was initially $>35 \mathrm{~kg} / \mathrm{m}^{2}$, compared to women with a body mass index was initially $<22 \mathrm{~kg} / \mathrm{m}^{2}$ and weight gain of $7.0-10.9 \mathrm{~kg}$ after the age of
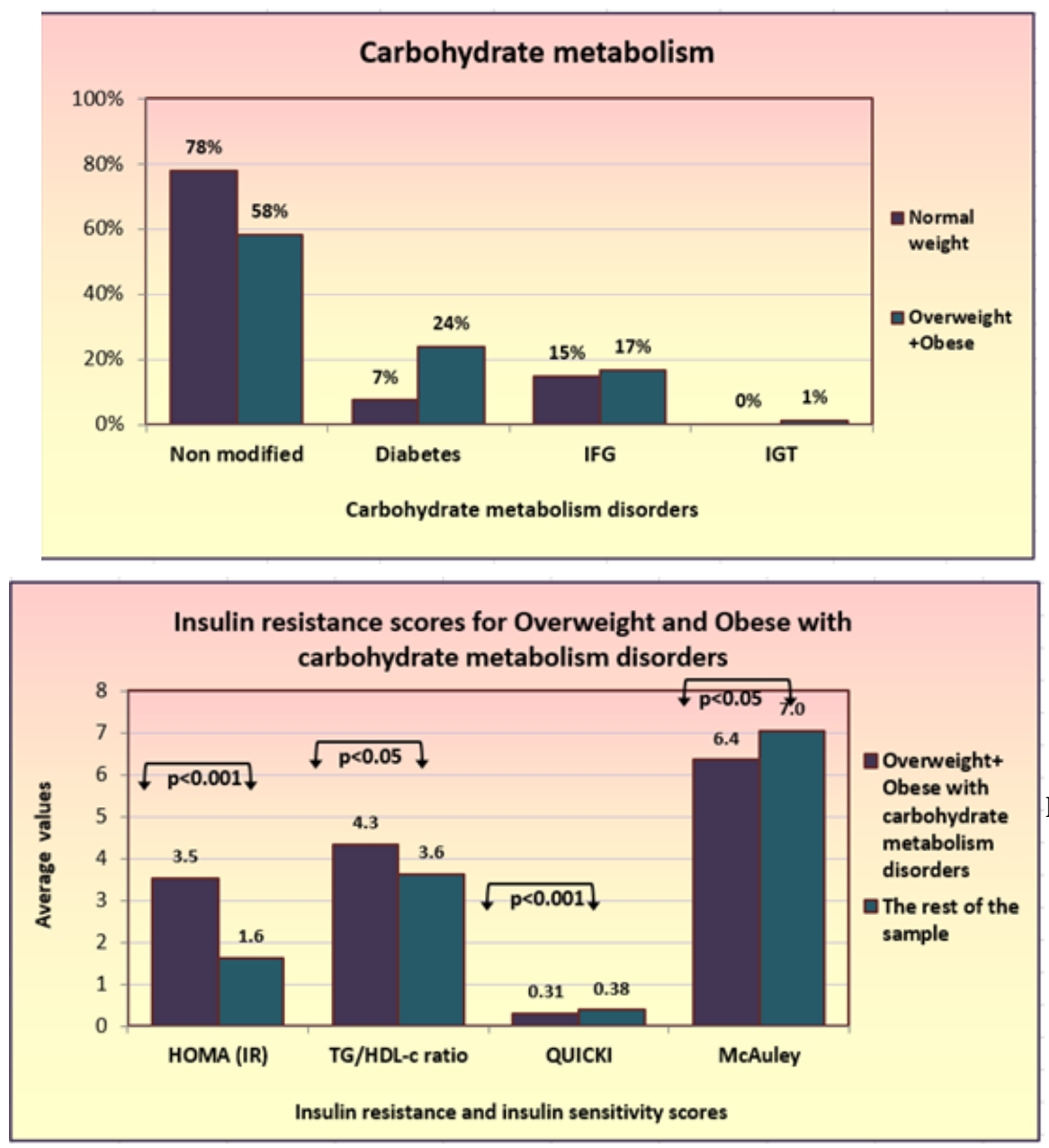

REV.CHIM.(Bucharest) $\$ 70 \diamond$ No. $10 \diamond 2019$
Fig. 1. Changes in the carbohydrate metabolism in the studied group (NW vs. $\mathrm{OW}+0)$

Fig. 2. Mean values of insulin resistance scores in overweight and obese patients with Carbohydrate metabolism disorder 

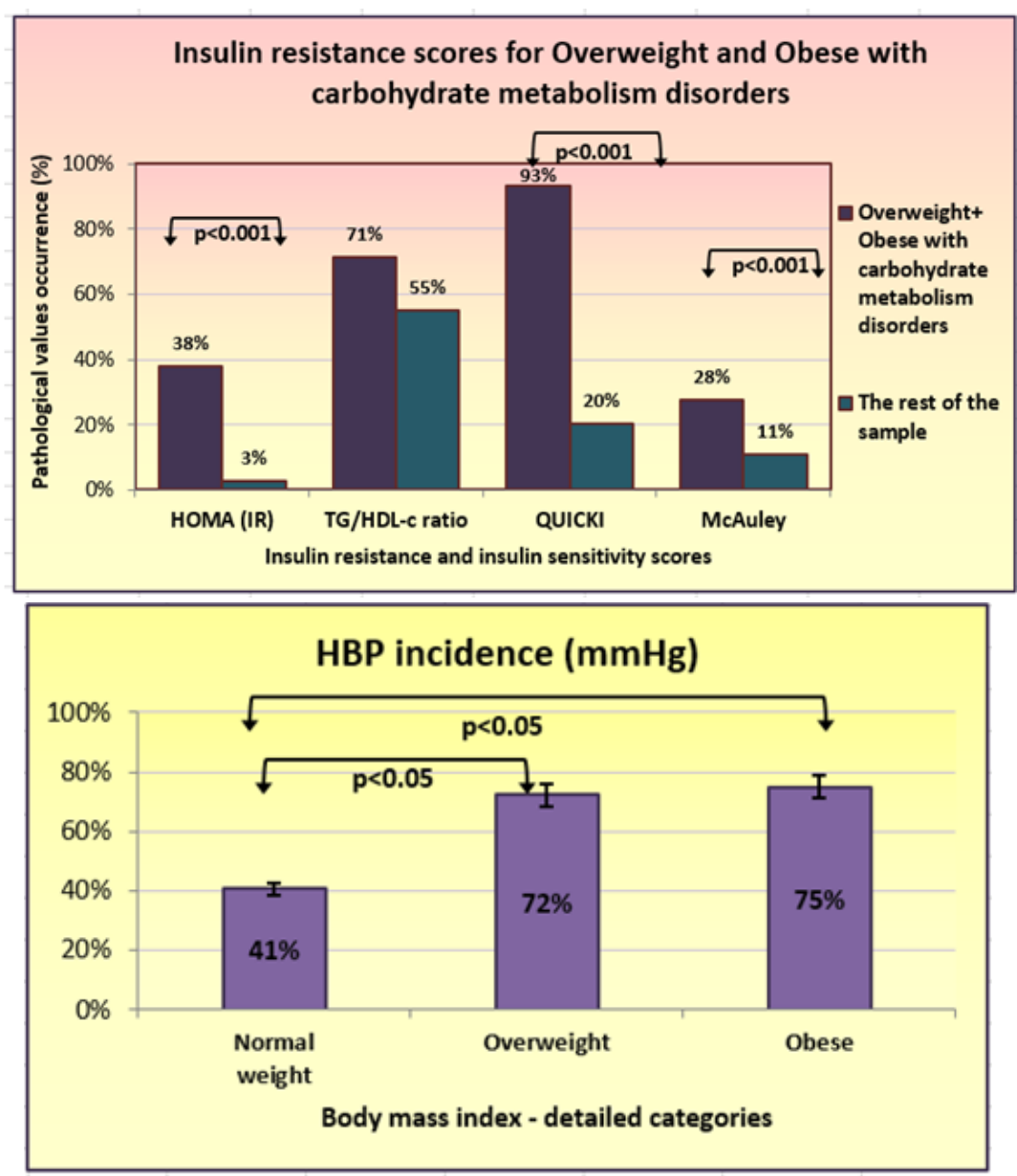

Fig. 3. Relationship between insulin resistance carbohydrate metabolism - weight status

Fig. 4. Prevalence of HBP normalweight versus overweight versus obese
18 years was associated with a 2 -fold increase in the risk of type 2 diabetes, the increase in risk being proportional to weight gain [31].

Some data from the literature describe that in the same degree of obesity, individuals may have normal blood glucose levels, impaired glucose tolerance or type 2 diabetes, the factors determining glycemic status being insulin sensitivity and reserve capacity of $\beta$-pancreatic cells [25] which is why we also studied 2 insulin sensitivity indexes (QUICKI, McAuley) and 2 insulin resistance indices (HOMA-IR, serum triglyceride ratio / total serum cholesterol). The present study demonstrated that mean HOMA-IR insulin resistance scores are highly significant $(p<0.001)$ and TGL / HDL-col significantly $(p<0.05)$ higher in overweight and obese patients with modified carbohydrate metabolism compared to the rest of the batch and are significantly lower significantly $(p<0.001)$ and statistically significant $(p<0.05)$ for the mean values of QUICKI insulin sensitivity scores, respectively McAuley.

The prevalence of HBP in overweight and obese patients

Hypertensive patients were considered to be those already known for this diagnosis and who were on antihypertensive therapy or not, and those subjects who were diagnosed with this pathology only at the time of inclusion.

The percentage of overweight and obese hypertensive patients is almost twice as high as the percentage of hypertensive normoponder, the difference being statistically significant $(p<0.05)$. At the detailed level of weight status subgroups, there are statistically significant differences $(p<0.05)$ betw een the prevalence of systemic hypertension in obese versus normoponderal and overweight versus obese (fig. 4).

Blood hypertension is a modifiable cardiovascular risk factor, one of the five defining elements of metabolic syndrome, the prevalence of metabolic syndrome hypertension in a 2010 study in the general population of Germany, Spain and Italy being of 36\%, 11\% and respectively $10 \%$ [32]. Of all the patients with hypertension, $61 \%$, $22 \%$ and $21 \%$ also had metabolic syndrome [32]. High blood pressure is a condition commonly associated with obesity, which has been confirmed by numerous epidemiological studies, eg in the Swedish Obesity Study, hypertension was present in $44-51 \%$ of the subjects studied [6,33].

Also, one study shows that, including at younger age, weight gain predisposes to early systemic arterial hypertension [34]. The study on 18 to 20 year old students showed that only a slight weight gain of 1.5 pounds $(0.68$ $\mathrm{kg}$ ) is sufficient to increase systolic blood pressure by 3-5 $\mathrm{mmHg}$ [34].

As we can see in our study, the prevalence of hypertension reaches about 2-fold higher values in overweight and obese patients compared to normoponderal patients ( $74 \%$ vs. $41 \%)$, statistically significant differences being obtained also in the case of overweight versus normoponderal

\section{The study of insulin resistance in overweight and obese patients}

For the assessment of insulin resistance, as I said above, 2 calculation formulas were used: the HOMA-IR index and serum triglyceride / HDL-cholesterol (TGL / HDL-col) ratio, and for the assessment of insulin sensitivity, 2 scores were calculated: QUICKI and McAuley.

The mean values for all four scores are statistically significantly different $(p<0.05)$ in overweight and obese versus normoponderal, higher for HOMA-IR and TGL / HDLcol ratio, respectively for QUICKI and McAuley score - Table 1,(fig. 5).

Insulin resistance occurs when body cells (hepatic, striatal, adipose) become less sensitive and possibly insulin- 


\begin{tabular}{|l|r|r|r|r|}
\hline & HOMA-IR & $\begin{array}{r}\text { TGL/HDL-COL } \\
\text { ratio }\end{array}$ & QUICKI & McAULEY \\
\hline Mann-Whitney U & 668.500 & 751.500 & 764.000 & 682.000 \\
Wilcoxon W & 1019.500 & 1129.500 & 3767.000 & 3685.000 \\
Z & -2.532 & -2.630 & -2.114 & -2.423 \\
\hline Asymp. Sig.(2-tailed) & .011 & .009 & .035 & .015 \\
\hline
\end{tabular}

Table 1

THE MANN-WHITNEY TEST RESULT APPLIED TO MEAN VALUES OF INSULIN RESISTANCE AND INSULIN SENSITIVITY SCORES

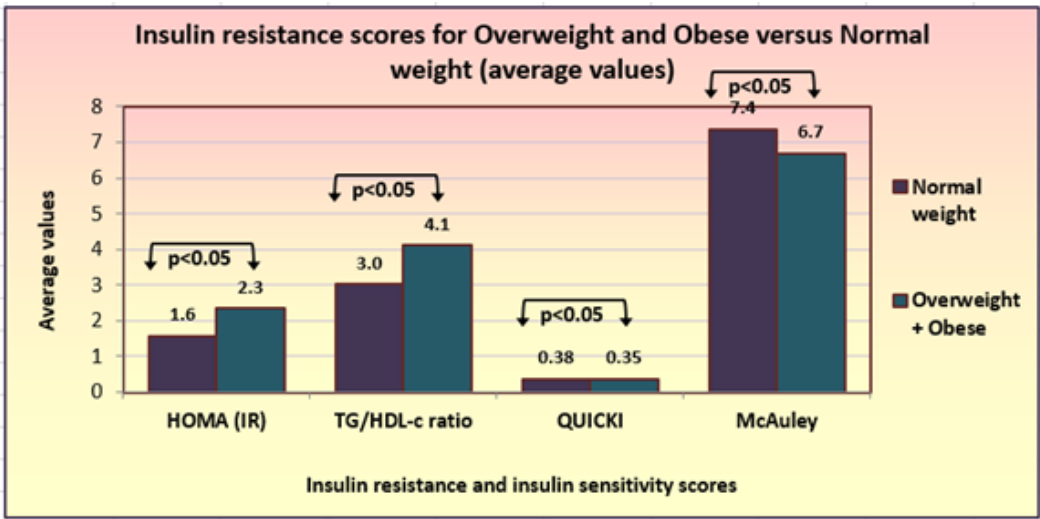

Fig. 5. The mean values of insulin resistance and insulin sensitivity scores

resistant, so that glucose can no longer be absorbed by cells and remains in the blood, being a trigger for the secretion of as much as possible insulin (hyperinsulinism) $[35,36,37]$. In fact, the mechanisms of insulin resistance in patients with obesity are much more complex: the increase in adipose cell diameter and infiltration of macrophages into adipose tissue leads to the release of proinflammatory cytokines that promote insulin resistance; additional contributions also bring about insulin secretion abnormalities in the insulin receptor signal [36]. These anomalies may result from obesity with relative increase in the level of free fatty acids and changes in insulin distribution, which accumulate in adipose tissue [36].

It is also known that normal weight patients may also have insulin resistance, called metabolic obese, with normal body weight, but with visceral adipose tissue growth; in agreement with several theories that analyze visceral adiposity, while in obese patients there is an increased flow of free fatty acids that reach the liver through splanchnic circulation, in those with abdominal fat lipolysis releases free fatty acids directly into the systemic circulation, avoiding hepatic metabolism [38-40].

A study by Reaven concludes that obese people with decreased and / or loss of insul in sensitivity are more likely to develop cardiovascular disease, but not all overweight or obese people are insulin resistant [41]. Moreover, insulin resistance leads to endothelial dysfunction, especially in combination with other traditional cardiovascular risk factors, but new direct mechanisms are proven: the existence of the same insulin-related abnormal cell signals in striatal muscles, adipose tissue and endothelial cells [42]. Some clinical trials demonstrate that nonpharmacological and pharmacological strategies targeting obesity and / or insulin resistance improve endothelial function and systemic inflammation, thus lowering the risk of cardiovascular disease [42].

In this study we demonstrated that there is a statistically significant difference in both insulin resistance and insulin sensitivity between the two large studies groups, overweight and obese versus normoponderal by the study of the four different scores.

\section{The prevalence of metabolic syndrome in overweight and obese patients.}

Metabolic syndrome (MS) is present in almost 3 quarters of the patient population (72\%), its prevalence being slightly higher in males than in females, but with no statistical significance. The prevalence of metabolic syndrome is double in overweight and obese compared to normoponderal, the difference being statistically significant $(p<0.001)$, this difference also beign present in women- Figure 6.

The prevalence of metabolic syndrome increases as the degree of obesity increases, the presence being twice as high, statistically significant $(p<0.001)$ in subjects with grade l obesity than in normoponderal ones and statistically

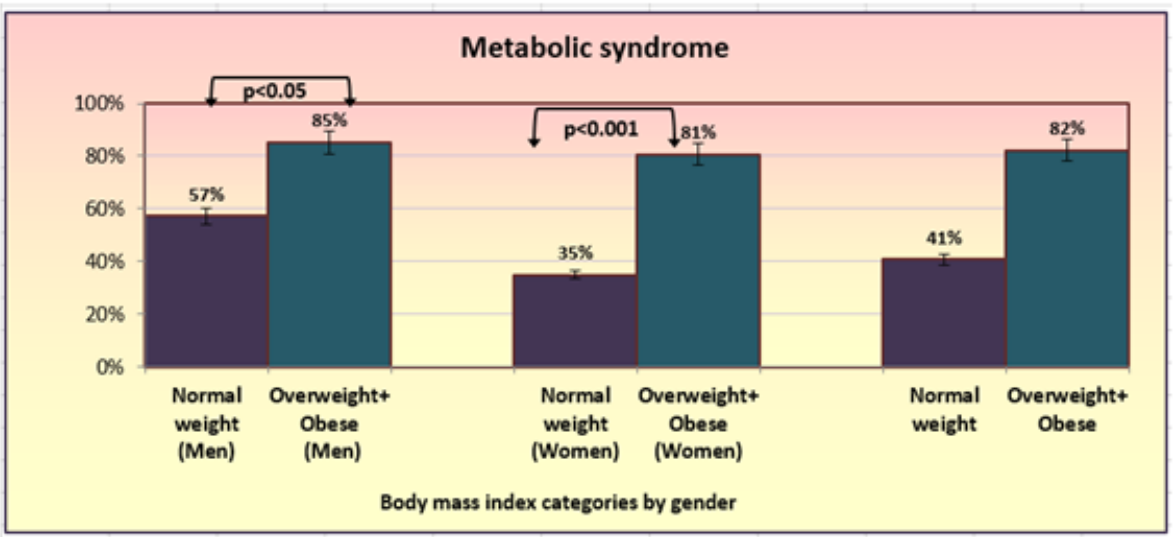

Fig. 6. The prevalence of metabolic syndrome according to weight status and sex 

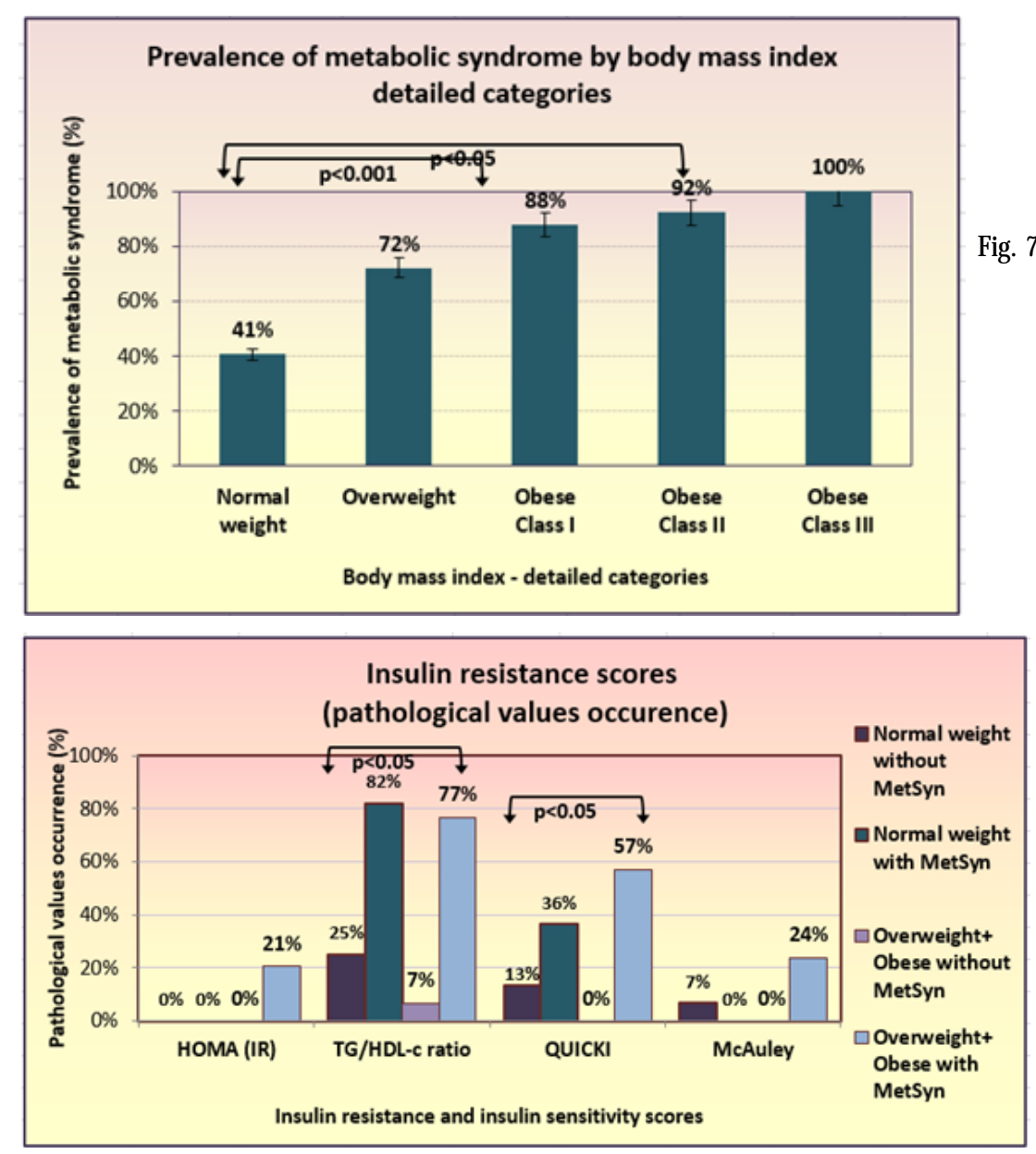

significantly higher $(p<0.05)$ at subjects with grade II obesity rather than normoponderal subjects - Figure 7.

Analyzing the percentage of patients with pathological values in the insulin resistance scores, according to international consensus, in each of the four categories of weight status and metabolic syndrome prevalence (NW$M S, N W+M S, O W+0-M S, O W+0+M S)$, the following statistically significant differences $(p<0.05)$ - Figure 8were found:

-The percentage of patients with pathological values at the TGL / HDL-Col ratio is higher at OW + 0 with MS compared to NW without MS and OW + O without MS;

-The percentage of patients with pathological values at the TGL / HDL-col ratio is higher in NW with MS compared to NW without MS and OW + O without MS;

-The percentage of patients with pathological values at the QUICKI score is higher at OW + 0 with MS compared to OW without MS and OW + O without MS.

As is well known, metabolic diseases are the major health problem of this century, including in our country [43]. The prevalence of obesity has increased threefold in the last 10 years in Romania, with a predisposition to metabolic diseases with extremely adverse consequences for the individual as well as for the family and society [5].

The prevalence of metabolic syndrome in the present study was $72 \%$, higher among males ( $79 \%$ ) and statistically significantly higher among overweight and obese compared to normoponderal ( $82 \%$ vs. $41 \%$ ), underlining the fact that the prevalence of metabolic syndrome increases significantly as obesity increases. The data from this study is comparable to population studies in the United States of America that demonstrated a $45 \%$ prevalence of metabolic syndrome in people over 65 years, given that in our study the mean age of subjects was 58 years $[44,45]$. Data from the literature on the prevalence of metabolic syndrome are different and often controversial. These
Fig. 7. The prevalence of metabolic syndrome according to detailed weight status
Fig. 8. he percentage of patients with pathological values at different insulin resistance scores based on weight status and prevalence of metabolic syndrome differences, including the present study, can be explained by the lower number of patients enrolled in our analysis, butalso by the definition used in the diagnosis of metabolic syndrome, criteria in which obesity is no longer considered mandatory for the diagnosis of metabolic syndrome and the value of pathological glycemia is e" $100 \mathrm{mg} \%[43,46$, 47].

It is known that the main pathogenetic link of the metabolic syndrome is insulin resistance, insulin hyperproduction leading to depletion of â-pancreatic cells and thus to hyperglycemia and type 2 diabetes even before this pathology is diagnosed when atherogenic dyslipidemia [35-37].

We also intend to study insulin resistance and insulin sensitivity through multiple scores among obese and overweight subjects who associate metabolic syndrome (HOMA-IR, TGL/ HDL-col, QUICKI, McAuley). We obtained statistically significant differences $(p<0.05)$ both by comparing batch of overweight and obese with metabolic syndrome with normoponderal without metabolic syndrome and by comparing overweight and obese groups with and without metabolic syndrome, thus proving that the metabolic syndrome is the main "culprit" for insulin resistance increased insulin sensitivity associated with weight gain.

Study limits: the existence of a small number of subjects with grade III obesityincluded in the study due to the initial exclusion criterion from the study of the presence of symptoms and / or diagnosis of cardiac disease.

\section{Conclusions}

Overweight and obese patients show changes in atherogenic lipid metabolism, glucose metabolism, diabetes being about 7 times more common among people with grade II and III obesity compared to normoponderal subjects. 
Systemic arterial hypertension and obesity have a directly proportional relationship, the prevalence of hypertension increasing with weight gain, overweight status increasing the risk of being hypertensive about 2 -fold.

Overweight and obese patients have both increased insulin resistance and low insulin sensitivity compared to normoponderal subjects, at risk of developing metabolic syndrome 2 times higher than normoponderal individuals. The metabolic syndrome is the main "culprit" for increased insulin resistance and low insulin sensitivity associated with weight gain.

In conclusion, this study has shown that the overweight and obese, although unknown to have heart disease, have significant metabolic changes, which are the first steps towards endothelial dysfunction, subclinical atherosclerosis and early cardiovascular disease.

\section{References}

1.*** WHO Media Center. In press. Available online at: http:// www.who.int/mediacentre/factsheets/fs311/en/Updated: J anuary 2015. 2.J AMES, PT., RIGBY, N., LEACH, R. Eur J Cardiovasc Prev Rehabil, 11 n0.1, 2004, p:3

3.*** CDC. Overweight and Obesity: adult overweight and obesity. 2014. Available online at: $h$ ttp://w ww.cdc.gov/obesity/adult/index.html 4.*** WEBSITE: www.who.int Access online at: 9th April 2019

5.*** STUDIUL ORO. In press. Available online at: http://www2.cmb.ro/ stire.php?id=1769. Access at: 9th April 2019.

6.BOOK: HANCU, N., ROMAN, G., VERESIU, IA., Diabetul zaharat, Nutripa of Bolile Metabolice, Tratat 2, Ed. Echinox, Cluj Napoca, 2010, p. $19,451,549$.

7.REIS, J P., ARANETA, MR., WINGARD, DL., MACERA, CA., LINDSAY, SP., MARSHALL, SJ ., Ann Epidemiol, 19, n0.2, 2009, p.134

8.LEWINGTON, S., CLARKE, R., QIZILBASH, N., PETO, R., COLLINS, R., Lancet, 360, nr. 9349, 2002, p. 1903

9.CONSTANTIN, B., POSTOLACHE, P., CROITORU, A., NEMES RM., J ournal Of Environmental Protection And Ecology; 16 no. 2, 2015, p:517-520

10.NEMES, RM., POP, CS., CALAGIU, D., DOBRIN, D., CHETROIU D., JANTEA, P., POSTOLACHE, P. Revista Medico-Chirurgicala, 120, no.1, 2016, p:34-39.

11.TSIGOS, C., HAINER, V., BASDEVANT, A., ET AL. , Obesity Facts, 1 , no. 2, 2008, p.106

12.ALBERTI, KG., ECKEL, RH., GRUNDY, SM., ET AL.,Circulation, 120 , no 16,2009 , p1640

13.MATTHEWS, DR., HOSKER, JP., RUDENSKI, AS., NAYLOR, BA., TEACHER, DF., TURNER, RC. Diabetologia, 28, 1985, p 412

14.KATZ, A., NAMBI, SS., MATHER, K., BARON, AD., FOLLMANN, DA., SULLIVAN, G., QUON, MJ., J Clin Endocrinol Metab, 85, nr 7, 2000, p 2402

15.MCAULEY, KA., WILLIAMS, SM., MANN, JI., WALKER, RJ ., LEDWISBARNED, NJ ., TEMPLE, LA., DUNCAN, AS. Diabetes Care, 24, 2001, p 460

16.BOOK: GABRIELA ROMAN. Educapia Terapeuticã în Sindromul Metabolic. Editura Echinox, Cluj, 2004, p 91

17.POIRIER, P., GILES, TD., BRAY, GA., ET AL. Arteriosclerosis, Thrombosis, and Vascular Biology, 26, 2006, p 968
18.VAN DEVENTER, HE., MILLER, WG., MYERS, GL., ET AL, Clin Chem,57, 2011, p490

19.TOTH, PP., Circulation, 111, 2005, p e89

20.BARTER, P., GOTTO, AM., LAROSA, J C., ET AL. New England J ournal of Medicine, 357, no 13, 2007, p 1301

21.GENEST, J., J. Inherit. Metab. Dis., 26, 2003, p 267

22.BERSOT, TP., PEPIN, GM., MAHLEY, RW. Am. Heart J., 146, 2003, p. 1052

23.DEGOMA, EM., DEGOMA, RL., RADER, DJ ., J Am Coll Cardiol., 51, no 23, 2008, p 2199

24.BREWER, HB., JR. Arterioscler Thromb Vasc Biol., 24, 2004, p 387 25.MIRANDA, PJ., DEFRONZO, RA., CALIFF, RM., GUYTON, JR., American Heart J ournal,149, no 1, 2005, p 33-45

26.KLOP, B., ELTE, JWF., CABEZAS, ME., Nutrients, 5, nr 4, 2013, p 1218

27.MCADAMS, M.A., VAN DAM, R.M., H.U, FB., Obesity, 15, 2007, p 188 28.IANOSI, E.S., DANTES, E., CSIPOR, A., SZATHMARY M., SOCACI A., RUSU, E., NEMES, R.M.,Rev. Chim. (Bucharest), 69, no.10, 2018, p. 2725-2727.

29.NEMES, R.M., POSTOLACHE, P., TINTILA, A., MIHALTAN, FD., PETRARIU, FD. Medical-Surgical J ournal, 119 , no. 1, 2015, p: 23-30 30. IANOSI, E.S., POSTOLACHE P., MACOVEI, L.A., SZATHMARY, M., SZASZ S., NEMES, R.M., JIMBOREAN, G. Rev. Chim.(Bucharest), 69, no. 7, 2018, p:1766-1769

31.COLDITZ, GA., MANSON, JE., HANKINSON, SE., J Womens Health.,6, no 1, 1997, p 49

32.SCHOLZE, J., ALEGRIA, E., FERRI, C., ET AL. BMC Public Health,10, 2010, p 529

33.BOGAERT, YE., LINAS, S., Nature Clinical Practice Nephrology, 5, no 2, 2009, p 101-111

34.BOOK: MARIANA, GRAUR, Editura Junimea, laio, 2004, p 185-207

35.ALBERTI, G., ZIMMET, P., SHAW, J., GRUNDY, SM., The IDF consensus worldwide definition of the METABOLIC SYNDROME, 2006. Available

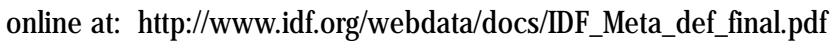
36.LOVRE, D., MAUVAIS-J ARVIS, F., J ama, 314, no 9, 2015, p 950

37.AGANOVI/E, I., DUSEK, T., EJIFCC, 18, no 1, 2007, p 3

38.RIDKER, PM., Circulation: Cardiovascular Quality and Outcomes, 2, 2009, p 279

39.CHOI, CHE., Cohen, P., eLife, 6, 2017, p e33298

40.NOAKES, TD., Clinical Chemistry, 64, no 1, 2018, p 7

41.REAVEN, GM., Medical Clinics of North America, 95, no 5, 2011, p 875

42.CABALLERO, AE., Obesity Research, 11, 2003, p 1278

43.COZMA, A., SITAR-TAUT, A., ORASAN, O., LEUCUTA, D., ET AL., Metabolic Syndrome and Related Disorders, 20, No 20, 2018, p 1

44.ZALESIN, KC., FRANKLIN, BA., MILLER, WM., ET AL., The Medical Clinics of North America, 95, no 5, 2011, p 919

45.BOOK: CALEEN, HB., BRAY, GA., Humana Press, New Jersey 2008, part I, Earl S. Ford and Simin Liu, p 75-84

46.BUDIN, C.E., MAIEREAN, A.D., IANOSI, E.S., SOCACI, A., BUZOIANU, A.D., ALEXESCU, T.G., OLTEANU, M., RUSU, E., MOLDOVAN, C.A., NEMES, R.M., Rev. Chim. (Bucharest), 70, no 2, 2019, p 449

47.DESPRES, JP., LEMIEUX, I., BERGERON, J., PIBAROT, P., MATHIEU, P., LAROSE, E., Arterioscler Thromb Vasc Biol., 28, no 6, 2008, p 1039

$\overline{\text { Manuscript received: } 25.02 .2019}$ 